\title{
Hydroxyestrogens inhibit angiogenesis in swine ovarian follicles
}

\author{
G Basini ${ }^{1}$, S Bussolati ${ }^{1}$, S E Santini ${ }^{1}$, F Bianchi ${ }^{2}$, M Careri ${ }^{2}$, A Mangia ${ }^{2}$, M Musci ${ }^{2}$ and F Grasselli ${ }^{1}$ \\ ${ }^{1}$ Dipartimento di Produzioni Animali, Biotecnologie Veterinarie, Qualità e Sicurezza degli Alimenti - Sezione di Fisiologia Veterinaria and ${ }^{2}$ Dipartimento di \\ Chimica Generale ed Inorganica, Chimica Analitica, Chimica Fisica, Università degli Studi di Parma, Via del Taglio, 8, Viale Usberti 17/A, 43100 Parma, Italy \\ (Correspondence should be addressed to G Basini; Email: basini@unipr.it)
}

\begin{abstract}
The rapid, controlled, and cyclical nature of angiogenesis in the ovarian follicle suggests the potential for sex steroids to influence neovascularization. Angiogenesis is regulated by a local balance between the levels of endogenous stimulators and inhibitors. Multiple lines of evidence suggest that estrogens stimulate angiogenesis via effects on endothelial cells. However, it is of outstanding value to investigate the negative control of this process. Since the main estrogen metabolites, 2-hydroxyestradiol and 4-hydroxyestradiol (4-OHE2) have been demonstrated to function as anti-estrogen in several estrogen-dependent organs; the aim of this study was to investigate their potential involvement in the modulation of follicular angiogenesis. Hydroxyestrogens were quantified in swine follicular fluid and their effects were studied on granulosa cell vascular endothelial growth factor (VEGFA) production and tested in an
\end{abstract}

angiogenesis bioassay. Our study documents that these molecules are physiologically present in swine follicular fluid and their concentrations significantly $(P<0 \cdot 001)$ increase during follicle development. Moreover, angiogenesis bioassay revealed that both hydroxyestrogens significantly $(P<0 \cdot 001)$ inhibited new vessel growth. We evidenced that the most potent negative effect is mediated by 4-OHE2. The anti-angiogenic potential of this molecule is also supported by its ability to inhibit $(P<0 \cdot 001)$ VEGFA production by granulosa cells. Increased knowledge in this area is of utmost importance for future therapeutic options to contrast infertility disorders associated with aberrant angiogenesis; this would be also very useful for the treatment of diseases characterized by disregulated angiogenesis and vascular regression.

Journal of Endocrinology (2008) 199, 127-135

\section{Introduction}

In adult organisms, angiogenesis is virtually absent under normal conditions. An exception takes place in the ovaries where neovascularization is imposed recurrently by cyclic development of transient structure and cyclic repair of damaged tissues (Fraser 2006). This observation suggests the potential for sex steroids to influence vessel growth. In particular, increased incidence in premenopausal females of diseases involving endothelial cell proliferation, such as Takayasu's arteritis and lupus, suggests a possible role for estrogens in angiogenesis (Ahmed et al. 1985, Shelhamer et al. 1985). Experimental evidence further supports the involvement of these steroids in physiological and pathological vascularization; among these, the finding that angiogenesis is impaired in estrogen receptor knockout mice and also the observation that estrogen receptor antagonists can inhibit endothelial cell proliferation (Losordo \& Isner 2001).

Within the ovarian follicle, which represents an outstanding system for studying the physiological process of angiogenesis (Basini et al. 2004, 2005, 2007a), it has been demonstrated that estradiol stimulates the expression of vascular endothelial growth factor (VEGFA) mRNA in bovine granulosa cell in vivo and in vitro (Shimizu \& Miyamoto 2007). In recent years, the pro-angiogenic mechanisms involved in follicular angiogenesis have been extensively studied while little is known about tempering factors. However, a deeper understanding of the molecular control of angiogenesis is needed in order to provide a novel approach to manipulate reproductive function; moreover, insight should be gained into the changes that precipitate the uncontrolled angiogenesis responsible for the growth of solid tumors. In a previous study (Basini et al. 2007b), we demonstrated that 2-methoxyestradiol is a potential physiological inhibitor of follicular angiogenesis. Since several lines of experimental evidence (Ho 2004, Salih et al. 2007) suggest that estrogen metabolites play an important role in angiogenesis control, our aim was to study the main hydroxyestrogens, 2-hydroxyestradiol (2-OHE2), and 4-hydroxyestradiol (4-OHE2), as factors potentially involved in the modulation of follicular angiogenesis; these metabolites have been demonstrated to function as anti-estrogens in several estrogen-dependent organs (Al-Hendy \& Salama 2006). To do so, we first attempted to quantify 2-OHE2 and 4-OHE2 concentrations in swine follicular fluid collected from follicles at different stages of development. Thereafter, the effects of both hydroxyestrogens on VEGFA production from swine granulosa cell were studied. In addition, using an angiogenesis bioassay developed in our laboratory (Basini et al. 2007a), we tested 2-OHE2 and 4-OHE2 on porcine aortic endothelial cell (AOC) growth in a three-dimensional fibrin gel matrix. 


\section{Materials and Methods}

All the reagents were obtained from Sigma unless otherwise specified.

\section{Follicular fluid and granulosa cell collection}

Swine ovaries were collected at a local slaughterhouse, placed in cold PBS $\left(4^{\circ} \mathrm{C}\right)$ supplemented with penicillin $(500 \mathrm{IU} / \mathrm{ml})$, streptomycin $(500 \mu \mathrm{g} / \mathrm{ml})$, and amphotericin $\mathrm{B}(3.75 \mu \mathrm{g} / \mathrm{ml})$, maintained in a freezer bag, and transported to the laboratory within $1 \mathrm{~h}$. After a series of washings with PBS and ethanol (70\%), follicles were divided into three classes corresponding to the diameter: small $(<3 \mathrm{~mm})$, medium $(3-5 \mathrm{~mm})$, and large follicles $(>5 \mathrm{~mm})$. Follicular fluid was collected with a 26 gauge needle from follicles of each class to determine 2-OHE2 and 4-OHE2 contents.

A 26 gauge needle was employed to aseptically harvest granulosa cells from follicles $>5 \mathrm{~mm}$, since we previously demonstrated (Basini et al. 2004) that large follicles are mostly involved in the angiogenic events. The cells were released in medium containing heparin $(50 \mathrm{IU} / \mathrm{ml})$, centrifuged for pelleting, and then treated with $0.9 \%$ pre-warmed ammonium chloride at $37^{\circ} \mathrm{C}$ for $1 \mathrm{~min}$ to remove red blood cells. Cell number and viability $(85 \pm 2 \%$ mean \pm s.E.M.) were estimated using a hemocytometer under a phase contrast microscope after vital staining with trypan blue $(0 \cdot 4 \%)$ of an aliquot of the cell suspension. The cells were seeded in culture medium (CM) composed by M199 supplemented with sodium bicarbonate $(2 \cdot 2 \mathrm{mg} / \mathrm{ml})$, BSA $(0 \cdot 1 \%)$, penicillin $(100 \mathrm{IU} / \mathrm{ml})$, streptomycin $(100 \mu \mathrm{g} / \mathrm{ml})$, amphotericin B $(2 \cdot 5 \mu \mathrm{g} / \mathrm{ml})$, selenium (5 ng/ml), and transferrin $(5 \mu \mathrm{g} / \mathrm{ml})$. Once seeded, the cells were incubated at $37^{\circ} \mathrm{C}$ under humidified atmosphere $\left(5 \% \mathrm{CO}_{2}\right)$.

\section{Gas chromatograph (GC)-mass spectrometry (MS) analysis}

GC-MS analysis was performed using a HP 6890 Series Plus GC (Agilent Technologies, Milan, Italy) equipped with Mass Selective Detector (MSD) 5973 (Agilent Technologies). Helium was used as the carrier gas at a flow rate of $1 \mathrm{ml} / \mathrm{min}$; the GC was operated in splitless mode (injection volume: $0 \cdot 5 \mu \mathrm{l}$ ) with the PTV injector (Agilent Technologies) equipped with a PTV multi-baffled liner (i.d. $1.5 \mathrm{~mm}$, Agilent Technologies) and operating under the following conditions: $70^{\circ} \mathrm{C}$ for $0.5 \mathrm{~min}$ and $700{ }^{\circ} \mathrm{C} / \mathrm{min}$ to $280^{\circ} \mathrm{C}$. Chromatographic separation was performed on a $30 \mathrm{~m} \times 0.25 \mathrm{~mm}, d_{\mathrm{f}} 0.25 \mu \mathrm{m}$ factor four capillary column equipped with a EZ-guard column (Varian, Torino, Italy). The following GC oven temperature program was applied: $70{ }^{\circ} \mathrm{C}, 30{ }^{\circ} \mathrm{C} / \mathrm{min}$ to $230{ }^{\circ} \mathrm{C}, 230^{\circ} \mathrm{C}$ for $8 \mathrm{~min}$, $10{ }^{\circ} \mathrm{C} / \mathrm{min}$ to $250^{\circ} \mathrm{C}, 30^{\circ} \mathrm{C} / \mathrm{min}$ to $310^{\circ} \mathrm{C}$, and $310^{\circ} \mathrm{C}$ for $15 \mathrm{~min}$. Transfer line and source were maintained at 250 and $230^{\circ} \mathrm{C}$ respectively. The mass spectrometer was operated in time selected ion monitoring mode (SIM) by recording the current of the following ions: from 0600 to $1020 \mathrm{~min} \mathrm{~m} / z$ 482, 369, 256 for 2-FE; and from 1020 to $1500 \mathrm{~min} \mathrm{~m} / z 576,463$, 421 for
4-OHE and 4-OHE. A solvent delay of 6 min was applied. The molecular ions were used for quantitation, whereas the corresponding ion ratios were used to confirm the identification of the analytes. A dwell time of $100 \mathrm{~ms}$ was used for all the ions. Preliminary full scan electron impact data were acquired to determine appropriate masses for SIM under the following conditions: ionization energy, $70 \mathrm{eV}$; mass range, 50-600 amu; and scan time, $3 \mathrm{scan} / \mathrm{s}$. All the analyses were performed setting the electron multiplier voltage at $1700 \mathrm{~V}$.

Signal acquisition and elaboration were performed using the HP Chemstation (Agilent Technologies).

\section{Solid-phase extraction (SPE)}

2-Fluoroestradiol (internal standard 2-FE, 99.9\% purity), (2-OHE2 and 4-OHE2, 98\% purity) were purchased from Steraloids (London, UK). Stock solutions were prepared in acetone at a concentration of $100 \mathrm{mg} / \mathrm{l}$ and stored at $-20^{\circ} \mathrm{C}$ for up to 2 weeks, whereas standard and working solutions were prepared daily by dilution from the stock solutions. To $1 \cdot 0 \mathrm{ml}$ follicular fluid spiked with $10 \mu \mathrm{g} / \mathrm{kg}$ ( $\mu \mathrm{g} / \mathrm{kg}$ refers to the follicle weight) of 2-FE, $1 \mathrm{ml}$ acetone was added drop by drop to obtain protein precipitation. After centrifugation $(400 \mathrm{~g}, 10 \mathrm{~min})$, the supernatant was applied to the SPE C18 cartridges (Supelco, Bellefonte, PA, USA), previously conditioned with $3 \mathrm{ml}$ diethyl ether. Elution was performed with $4 \mathrm{ml}$ ether that was then evaporated to dryness under a nitrogen stream before the derivatization process.

\section{Derivatization}

An aliquot of $15 \mu \mathrm{l}$ dry toluene (reaction solvent) and $5 \mu \mathrm{l}$ trifluoroacetic anhydride (derivatizing agent) were added to sample extract. The derivatization procedure was carried out for $10 \mathrm{~min}$ at $30^{\circ} \mathrm{C}$. At the end of the reaction, the derivatized samples were submitted to GC-MS analysis.

\section{VEGFA production}

The $10^{6}$ granulosa cells in $1 \mathrm{ml} \mathrm{CM}+1 \%$ fetal calfserum (FCS) were seeded in each well of a 24 -well plate, treated with 1,10 , or $100 \mathrm{ng} / \mathrm{ml}$ of 2-OHE2 or 4-OHE2 and incubated for $48 \mathrm{~h}$. VEGFA content in culture media was quantified by an ELISA (Quantikine, R\&D System, Minneapolis, MI, USA); this assay, developed for human VEGFA detection, has been validated for pig VEGFA (Barboni et al. 2000). The assay sensitivity was $8.74 \mathrm{pg} / \mathrm{ml}$, the inter- and intra-assay CVs were always less than 7\%. A Spectra Shell microplate reader (SLT Spectra, Milan, Italy), set to read $450 \mathrm{~nm}$ emission, was used to quantify the reaction product.

\section{Angiogenesis bioassay}

Endothelial cell culture An immortalized porcine aortic endothelial cell line (AOC; Carrillo et al. 2002) was generously provided by José Yelamos (Hospital Universitario Virgen de la 
Arrixaca, El Palmar, 30120 Murcia, Spain). In all experiments, AOC at 19th passage was used and seeded in CM.

\section{Three-dimensional endothelial cell culture on a} fibrin gel support The microcarrier-based fibrin gel angiogenesis assay was performed as described by Grasselli et al. (2003) with some modifications. Briefly, $12.5 \mathrm{mg}$ gelatin-coated cytodex-3 microcarriers in $1 \mathrm{ml}$ PBS were incubated for $3 \mathrm{~h}$ to hydrate. After two washings in PBS and one in $\mathrm{CM}$, the microcarriers were put in flasks containing $5 \mathrm{ml} \mathrm{CM}$; AOC $\left(5 \times 10^{5}\right)$ were added and cultured for $24 \mathrm{~h}$ in order to let the endothelial cells coat the microcarriers. For the fibrin gel preparation, $40 \mu \mathrm{l}$ microcarriers covered by AOC were pipetted into 6-well plates containing a solution of fibrinogen ( $1 \mathrm{mg} / \mathrm{ml} \mathrm{PBS,} \mathrm{pH} 7 \cdot 6)$, added with $1250 \mathrm{IU}$ thrombin $(250 \mu \mathrm{l})$. Fibrin gels were allowed to polymerize for $30 \mathrm{~min}$ at $37^{\circ} \mathrm{C}$, and then they were equilibrated for $60 \mathrm{~min}$ with $2 \mathrm{ml} \mathrm{M199.} \mathrm{After} \mathrm{a} \mathrm{change} \mathrm{of} \mathrm{the} \mathrm{medium,} \mathrm{AOC} \mathrm{were}$ treated with VEGFA (100 ng/ml; PeproTech EC Ltd, London, UK) in the presence or absence of 1,10 , or $100 \mathrm{ng} / \mathrm{ml} 2-\mathrm{OHE} 2$ or 4-OHE2. The plates were incubated at $37^{\circ} \mathrm{C}$ under humidified atmosphere $\left(5 \% \mathrm{CO}_{2}\right)$. AOC was cultured for $96 \mathrm{~h}$, renewing totally the treatment after $48 \mathrm{~h}$ as described above.

Quantification of AOC growth on fibrin gel matrix Endothelial cell proliferation in the fibrin gel matrix was evaluated by means of the public domain NIH Program Scion Image Beta 4.02 (Scion Corporation, Frederick, MA, USA, http://rsb.info.nih.gov/nih-image/). Ten pictures were taken for each gel at 48 and $96 \mathrm{~h}$; images were converted into gray scale, resized to 50\% (Paintbrush Software, MS Office), and saved as Bitmap 24 bit format compatible with Scion. The modified images were then imported into the program and the measurements were made drawing the perimeter of the area occupied by AOC expressed as number of pixel. In order to validate the measurement of the area covered by AOC in fibrin gels as a reliable method to evaluate cell proliferation, fibrin gels were stained by the nuclear dye bisbenzimide (Hoechst 33258, $20 \mu \mathrm{g} / \mathrm{ml}$ in PBS for $60 \mathrm{~min}$ ) and examined by the fluorescence microscope. This procedure was performed 20 times; for each experiment, the number of nuclei was counted under fluorescence and pictures of the area covered by AOC were taken in order to measure the surface covered in the fibrin gel. A strong correlation was observed between the area covered by AOC and the number of nuclei found in the same area $(r=0 \cdot 96)$.

\section{Statistical analysis}

Method validation was carried out to meet the acceptance criteria for bioanalytical method validation (Guidance for Industry, Bioanalytical Method Validation 2001).

Instrumental detection (LOD) and quantitation (LOQ) limits were calculated according to EURACHEM guidelines (EURACHEM Guide 1998 http://www.eurachem.ul.pt/).
Table 1 Hydroxyestrogens content $(\mu \mathrm{g} / \mathrm{l})$ in swine follicular fluid

\section{Follicle class}

\begin{tabular}{|c|c|c|}
\hline Small & Medium & Large \\
\hline $0 \cdot 27 \pm 0 \cdot 04^{\mathrm{a}}$ & $1 \cdot 16 \pm 0 \cdot 36^{b}$ & $5 \cdot 05 \pm 0 \cdot 10^{\mathrm{C}}$ \\
\hline ND & $1.65+0.04^{\mathrm{a}}$ & $6.92+0.03^{b}$ \\
\hline
\end{tabular}

Data are expressed as means \pm S.E.M. Different letters in the same row indicate a significant difference $(P<0 \cdot 001)$. ND, not detected.

Once calculated, LOQ was tested for accuracy and precision to meet the previously cited international criteria.

The presence of matrix effect was evaluated by comparing the slopes of the regression models (five levels, three replicated measurements for each level) obtained using the external standard and the standard addition method respectively. Homoschedasticity was verified by applying the Bartlett test; lack-of-fit and Mandel's fitting test were also performed to check the goodness of fit and linearity (Funk et al. 1995).

The significance of the intercept (significance level 5\%) was established by a $t$-test.

Repeatability and inter-day precision were calculated in terms of relative standard deviation $(\mathrm{RSD} \%)$ on three concentration levels (at the LOQ level, at the final concentration of 5 and $20 \mu \mathrm{g} / \mathrm{kg}$ ) performing five replicates at each level.

The accuracy was calculated in terms of recovery rate (RR\%) as follow:

$\operatorname{RR} \%=\frac{c_{1}-c_{2}}{c_{3}} \times 100$

where $c_{1}$ is the concentration of the fortified sample, $c_{2}$ is the concentration of the sample before fortification, and $c_{3}$ is the concentration of fortification. Three different concentration

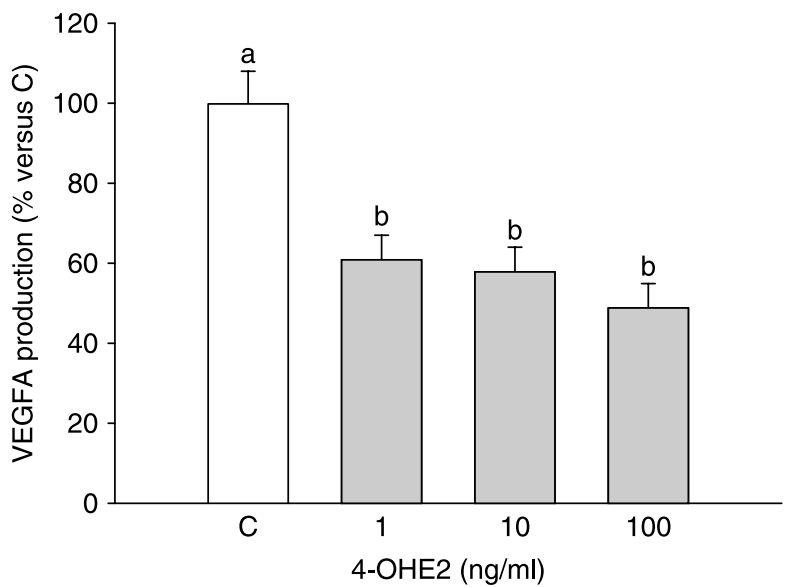

Figure 1 Effect of the treatment with 4-OHE2 (1, 10, and $100 \mathrm{ng} / \mathrm{ml})$ for $48 \mathrm{~h}$ on VEGFA production by swine granulosa cell. Different letters indicate a significant difference $(P<0 \cdot 001)$ among treatments as calculated by ANOVA and Scheffè's $F$ test. 
Table 2 Effect of 2-hydroxyestradiol on aortic endothelial cell (AOC) growth

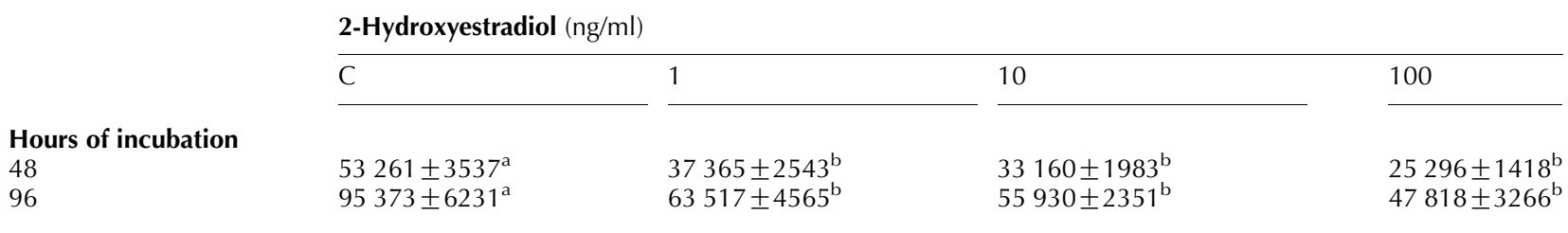

Values in the same row with different letters are significantly $(P<0 \cdot 001)$ different. Data represent the area covered by AOC in the fibrin gel (number of pixel; means \pm S.E.M).

levels (low, medium, and high) with five replicated measurements were analyzed. The extraction yield in terms of percent recovery was calculated by comparing the results obtained from the injection of pure standards $(n=3)$ with those related to the analysis of follicular fluids containing the same amount of analyte $(n=3)$.

Stability, expressed as percentage of the initial concentration of the hormone in the follicular fluid samples analyzed the day after the sampling, was evaluated in terms of freeze-thaw stability (storage at $-80{ }^{\circ} \mathrm{C}$ ), short-term stability, and long-term stability.

As for the other parameters, they were examined at least four times (6 replicates/treatment). Experimental data are presented as mean \pm s.E.M.; statistical differences between treatments were calculated with Multifactorial ANOVA using Statgraphics package (STSC Inc., Rockville, MD, USA). When significant

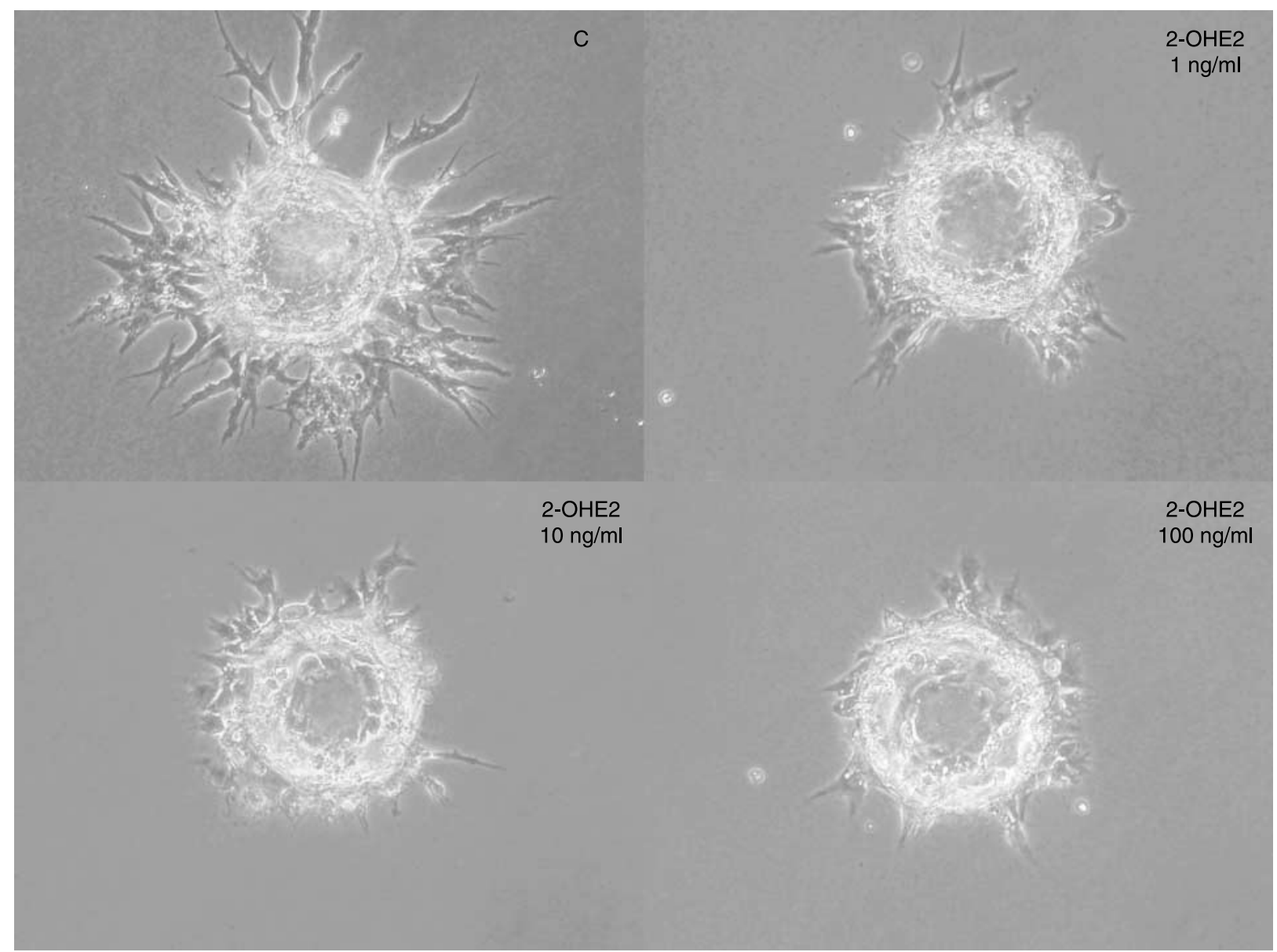

Figure 2 Phase contrast micrographs showing AOC growth at $48 \mathrm{~h}$ in fibrin gel matrix. Cells were cultured in CM or treated with 2-OHE2 at the concentrations of 1,10 , or $100 \mathrm{ng} / \mathrm{ml}$. 


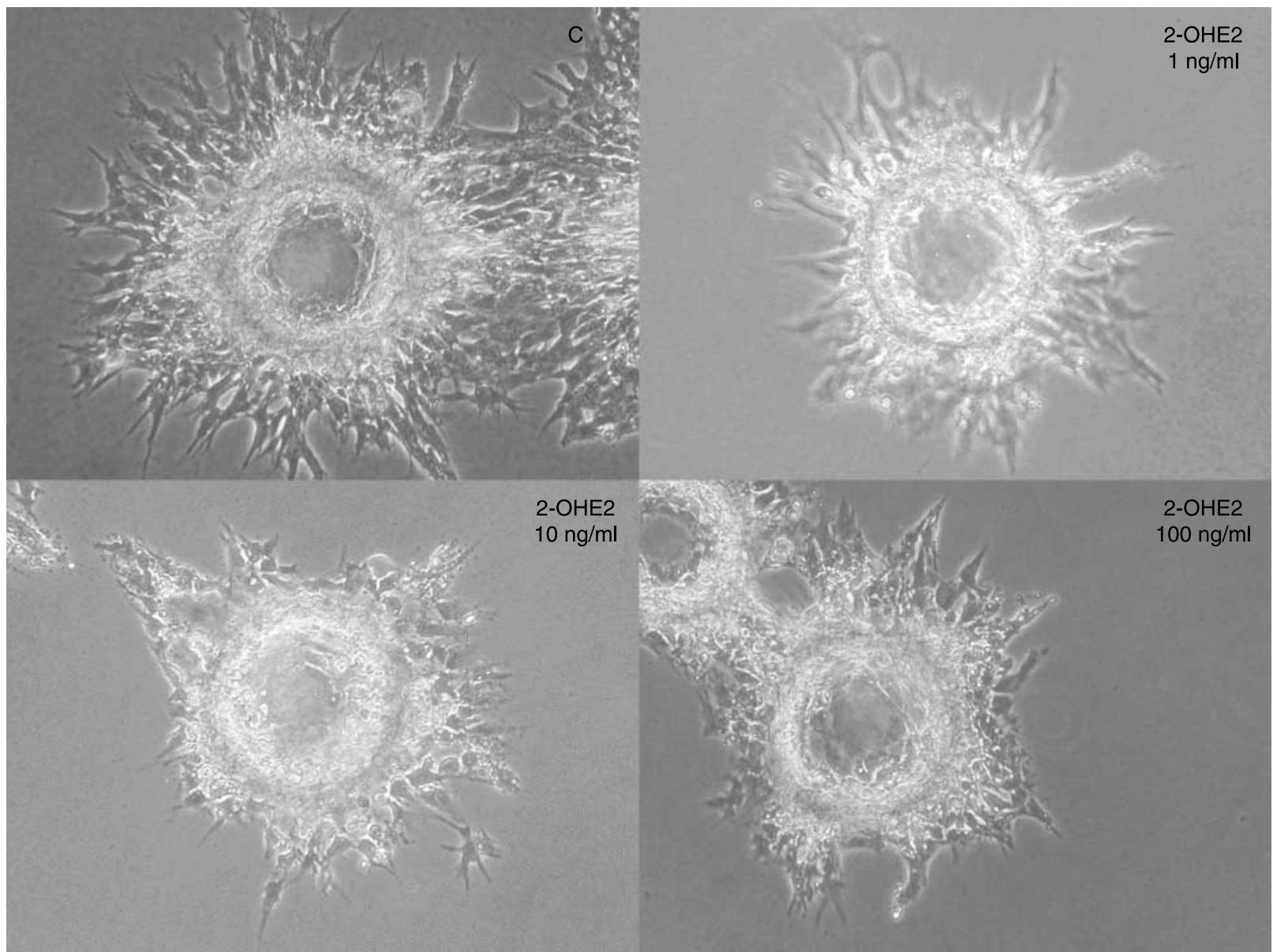

Figure 3 Phase contrast micrographs showing AOC growth at $96 \mathrm{~h}$ in fibrin gel matrix. Cells were cultured in CM or treated with 2-OHE2 at the concentrations of 1,10 , or $100 \mathrm{ng} / \mathrm{ml}$.

differences were found, means were compared by Scheffe's $F$ test; $P<0.05$ were considered to be statistically significant.

\section{Results}

Validation of 2-OHE2 and 4-OHE2 assays

The determination of the hydroxyestrogens' content in follicular fluid samples was carried out after method validation. Instrumental detection and quantitation limits were calculated using standard solutions. Very low LOD and LOQ values were determined, LOQ being equal to 0.2 and $0 \cdot 8 \mu \mathrm{g} / \mathrm{kg}$ for 2-OHE2 and 4-OHE2 respectively, the LOD values were about three times lower. The presence of the matrix effect was assessed by comparison of the calibration lines calculated using the external standard and the standard addition method, whereas an excellent precision with RSD $\%$ lower than $6 \%$ characterized the SPE-GC-MS method. Extraction yields higher than $82 \%$ and recoveries in the $85( \pm 4)-93( \pm 5) \%$ $(n=3)$ proved the accuracy of the developed method. Owing

Table 3 Effect of 4-hydroxyestradiol on aortic endothelial cell (AOC) growth

\begin{tabular}{|c|c|c|c|c|}
\hline & \multicolumn{4}{|c|}{ 4-Hydroxyestradiol (ng/ml) } \\
\hline & $\bar{C}$ & 1 & 10 & 100 \\
\hline \multicolumn{5}{|l|}{ Hours of incubation } \\
\hline $\begin{array}{l}48 \\
96\end{array}$ & $\begin{array}{l}53261 \pm 3537^{a} \\
95373+6231^{a}\end{array}$ & $\begin{array}{l}29632 \pm 3066^{b} \\
54764+2790^{b}\end{array}$ & $\begin{array}{l}23412 \pm 1550^{b} \\
45542+3787^{c}\end{array}$ & $\begin{array}{l}23516 \pm 2363^{b} \\
36216+1834^{c}\end{array}$ \\
\hline
\end{tabular}

Values in the same row with different letters are significantly $(P<0.001)$ different. Data represent the area covered by AOC in the fibrin gel (number of pixel; means \pm S.E.M). 


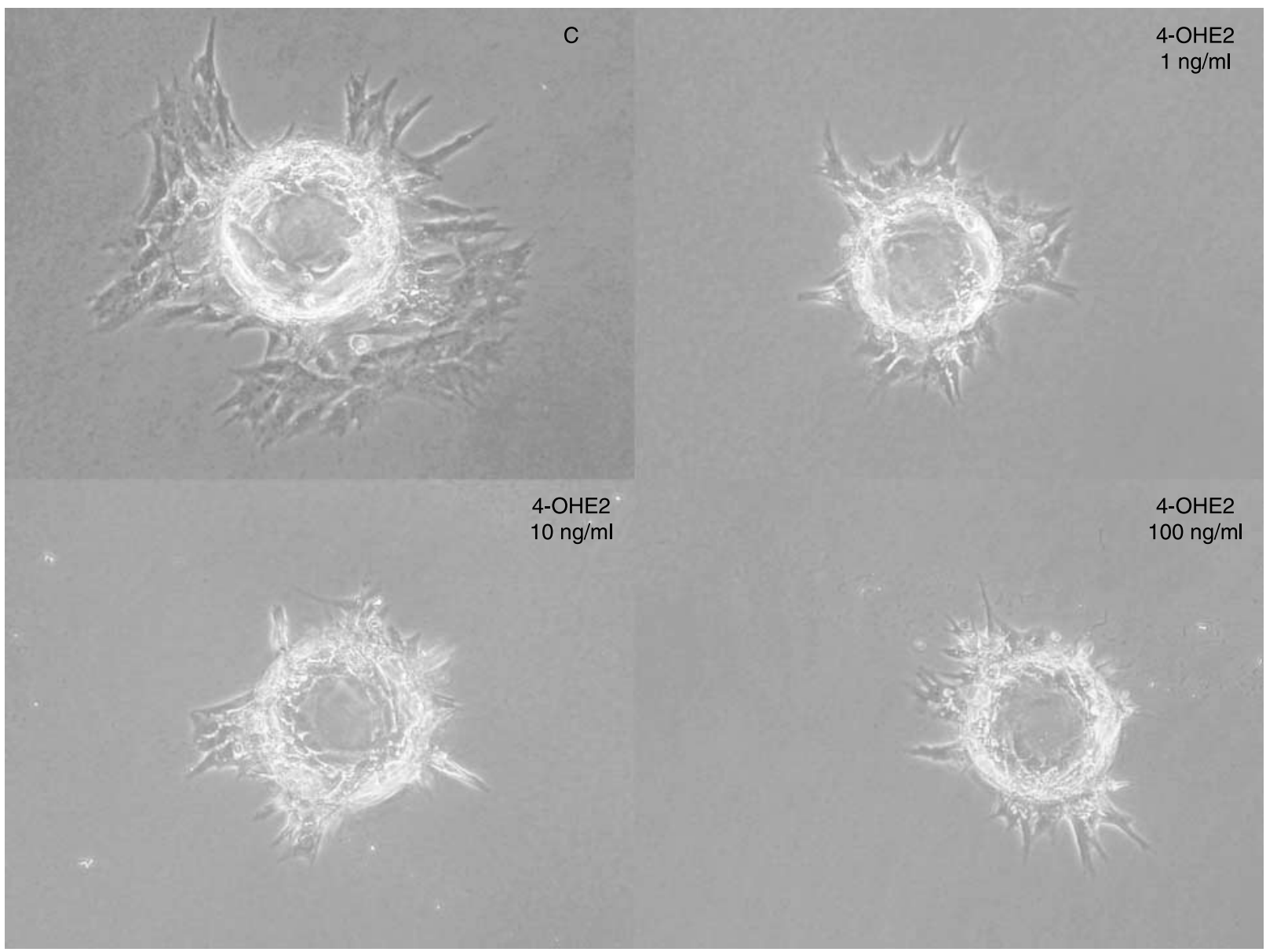

Figure 4 Phase contrast micrographs showing AOC growth at $48 \mathrm{~h}$ in fibrin gel matrix. Cells were cultured in CM or treated with 4-OHE2 at the concentrations of 1,10 , or $100 \mathrm{ng} / \mathrm{ml}$.

to the presence of labile hydroxyl groups, the stability of the investigated hormone in the time was also evaluated. Data obtained after going through three freeze and thaw cycles proved that no degradation of the investigated analytes occurred when both the matrix (storage at $-80{ }^{\circ} \mathrm{C}$ ) and the stock solutions (storage at $-20^{\circ} \mathrm{C}$ ) were maintained at room temperature just for the thawing time. Under these circumstances, no significant differences $(P>0 \cdot 05)$ among the chromatographic responses obtained before, during, and after the freeze and thaw cycles at room temperature were observed. As for the short-term storage, a relevant degradation of the analytes was evidenced by maintaining both the stock solutions and the matrix at room temperature for more than $4 \mathrm{~h}$ after thawing, thus observing an evident decrease in the chromatographic responses, with strong differences from the initial concentration levels. Concerning the long-term stability in the case of the stock solutions, it was proved that the recommended storage temperature $\left(-20{ }^{\circ} \mathrm{C}\right)$ could be maintained for up to 2 weeks, whereas shorter times (10 days) and lower temperatures $\left(-80^{\circ} \mathrm{C}\right)$ were required for the preservation of the follicular fluids.
More precisely, samples had to be maintained at $-80^{\circ} \mathrm{C}$ for a maximum of 10 days, with differences from the initial values always lower than $5 \%$.

\section{2-OHE2 and 4-OHE2 contents in follicular fluid}

The concentration of 2-OHE2 significantly increased $(P<0 \cdot 001)$ during follicle growth (Table 1), quadruplicating in medium follicles and appearing almost 20 times higher in large follicles than small ones. On the contrary, 4-OHE2 was impossible to quantify in small follicles, detectable in medium follicles, and became four times higher in the large ones.

\section{VEGFA production}

Basal VEGFA production by granulosa cells amounted to $960 \pm 42 \mathrm{pg} / \mathrm{ml}$ (mean \pm s.E.M.) The treatment with 2-OHE2 did not affect VEGFA production. On the contrary, 4-OHE2 at all concentration tested significantly $(P<0 \cdot 001)$ inhibited VEGFA output $(P<0 \cdot 001 ;$ Fig. 1$)$. 


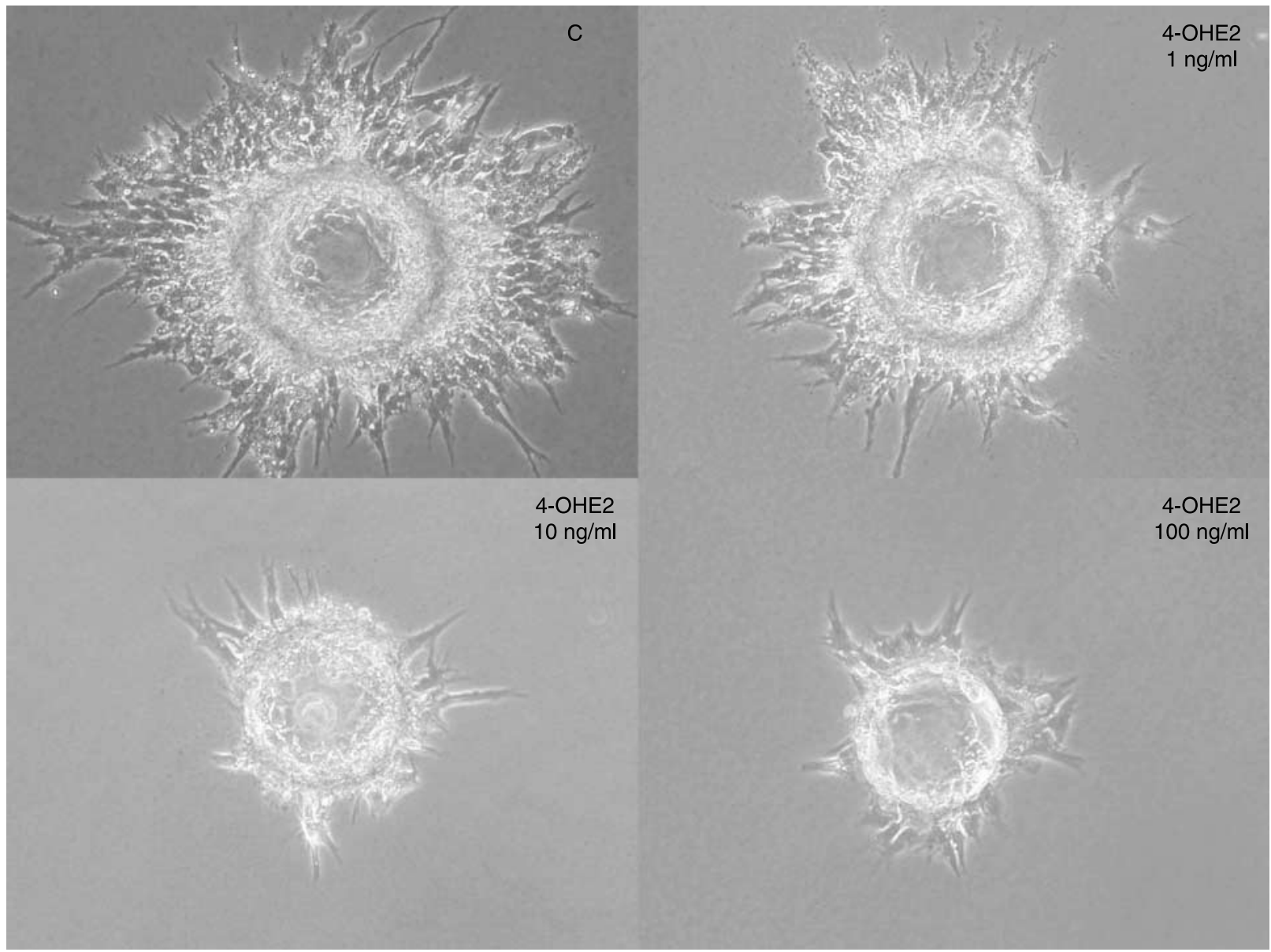

Figure 5 Phase contrast micrographs showing AOC growth at $96 \mathrm{~h}$ in fibrin gel matrix. Cells were cultured in CM or treated with 4-OHE2 at the concentrations of 1,10 , or $100 \mathrm{ng} / \mathrm{ml}$.

\section{Effect of 2-OHE2 and 4-OHE2 on AOC growth}

AOC proliferation significantly $(P<0 \cdot 001)$ increased with time in control groups; the area covered by AOC almost doubled during the 48-h incubation shifting from $53261 \pm$ 3537 to $95373 \pm 6231$ pixels. AOC incubated with 2-OHE2 showed a growth rate significantly reduced $(P<0 \cdot 001)$ both after 48- and 96-h incubation. No differences were found among the different concentrations tested $(P<0 \cdot 001$; Table 2 , Figs 2 and 3). The addition of 4-OHE2 to fibrin gel decreased $(P<0 \cdot 001)$ AOC proliferation: all the concentrations were equally effective after $48 \mathrm{~h}$ while after $96 \mathrm{~h} 10$ and $100 \mathrm{ng} / \mathrm{ml}$ were the most effective. Moreover, the area covered by AOC in fibrin gel was inhibited more efficiently $(P<0.01)$ by the treatment with 4-OHE2 than with 2-OHE2 at both the end time point for each concentration tested (Table 3, Figs 4 and 5).

\section{Discussion}

The development of the ovarian follicle is a complex process involving mechanisms that are similar to wound healing and tumor formation. The proliferation rate of endothelial cells in the developing follicle is much higher than that of rapidly growing tumors (Neeman et al. 1997), suggesting that this structure resembles a 'transitory tumor'. However, in contrast to tumor angiogenesis, this process is transient and strictly controlled within the ovary.

Anti-angiogenic factors may represent a potential mechanism to balance angiogenesis; although different anti-angiogenic molecules have been identified (Sato 2006), little is known about the negative control of vascularization in the ovary. Several lines of experimental evidence suggest that estrogen and other sex steroids directly modulate angiogenesis (Losordo \& Isner 2001). In particular, we previously evidenced that 2-methoxyestradiol, a naturally occurred estradiol derivative, inhibits ovarian angiogenesis (Basini et al. 2007a,b).

The present study was therefore addressed to explore the potential involvement of other major estradiol metabolites, 2-OHE2 and 4-OHE2, in the control of follicular angiogenesis. First of all, we aimed to assess the physiological presence of the above-mentioned hydroxyestrogens in follicular fluid. Unfortunately, a simple, specific, and sensitive 
assay capable of detecting these hormones in a complex matrix, such as follicular fluid, was absent. Therefore, a SPEGC-MS method was developed and validated for the determination of hydroxyestrogens in follicular fluid samples. Validation was carried out following the guidelines for bioanalytical methods, thus proving the capability of the method used for quantitation of the investigated estrogen metabolites at trace levels in complex matrices like follicular fluid samples. The developed method is characterized by detection of low concentration and quantitation limits as well as by excellent precision and accuracy. Our results demonstrate the presence of hydroxyestrogens in swine follicular fluid; moreover, their concentrations significantly increase during follicle growth.

Evidence exists which supports the hypothesis that these hormones are not mere catabolites. Instead, they would act as autocrine or paracrine factors driving follicle development (Spicer \& Hammond 1989, Spicer et al. 1990, Mishra \& Joy 2006). Their function in ovarian physiology is well-known, while their effects on local vessel growth are still to be clarified. A potent proangiogenic effect of estradiol has been evidenced (Losordo \& Isner 2001). Estradiol induces endothelial proliferation and migration mediated by the classic estrogen receptor that is expressed by endothelial cells (Foresta et al. 2007). In addition, the possibility that VEGFA may be partially responsible for the estradiol angiogenic action has been suggested by several findings (Wijayagunawardane et al. 2005). Estradiol metabolism generates hormones with distinct biologic activity (Grow 2002); in particular, it is aromatically hydroxylated by the cytochrome 1A1 and 1B1 group of enzymes to produce hydroxyestrogens, which have been demonstrated to act as anti-estrogens in several estrogen-dependent systems such as the breast (Raju et al. 2000) and uterus (Salama et al. 2006). There is now convincing evidence that the natural estrogen metabolite 2-methoxyestradiol is able to inhibit angiogenesis in several organs such as the ovaries, stomach, and prostate (Basini et al. 2007b, Lin et al. 2007, Van Veldhuizen et al. 2008). Other anti-angiogenic factors at ovarian level are represented by progesterone (Jaggers et al. 1996), prostaglandins (Girsh et al. 1995), and metalloproteases, since the principal step in angiogenesis is degradation of the basement membrane (Auerbach \& Auerbach 1994). Our present study documents, for the first time to our knowledge, that 2-OHE2 and 4-OHE2 estradiol metabolites are potentially involved in the negative balance of angiogenic process. We could argue that, as evidenced for 2-methoxyestradiol, hydroxyestrogens might reduce endothelial cell proliferation by inhibiting microtubule dynamics (Amorino et al. 2000). Moreover, similar to 2-methoxyestradiol (Becker et al. 2008), 2-OHE2, and 4-OHE2 could inhibit hypoxia-inducible factor-1 $\alpha$ that has been documented to play a key role in the VEGFA-induced angiogenesis (Basini et al. 2004). Further studies are needed in order to identify the mechanisms of action of these molecules in the follicular physiology.

\section{Concluding remarks}

Taken together, our data suggest that hydroxyestrogens 2-OHE2 and 4-OHE2, physiologically present in swine follicular fluid, can potentially exert an inhibitory effect on follicular neoangiogenesis. The most potent negative effect could be mediated by 4-OHE2 that has been shown to be capable of inhibiting the production of the main proangiogenic peptide, VEGFA, by granulosa cells.

Since dysfunctional or uncontrolled angiogenesis is involved both in the ovarian failure and in different diseases, clinical medicine may profit from understanding these control mechanisms in order to set up new methods to regulate fertility and to evaluate new therapeutic options for angiogenesis-dependent diseases.

\section{Declaration of interest}

The authors declare that there is no conflict of interest that could be perceived as prejudicing the impartiality of the research reported.

\section{Funding}

This research was supported by a FIL and MIUR PRIN grants.

\section{Acknowledgements}

We would like to thank Prof. Yelamos (Department of Biochemistry, Molecular Biology and Immunology, Facultad de Medicina, Universidad de Murcia, Spain) for supplying AOC.

\section{References}

Ahmed SA, Penhale WJ \& Talal N 1985 Sex hormones, immune responses, and autoimmune diseases: mechanisms of sex hormone action. American Journal of Pathology 121 531-551.

Al-Hendy A \& Salama SA 2006 Catechol-O-methyltransferase polymorphism is associated with increased uterine leiomyoma risk in different ethnic groups. Journal of the Society for Gynecologic Investigation 13 136-144.

Amorino GP, Freeman ML \& Choy H 2000 Enhancement of radiation effects in vitro by the estrogen metabolite 2 -methoxyestradiol. Radiation Research 153 384-391.

Auerbach W \& Auerbach R 1994 Angiogenesis inhibition: a review. Pharmacology and Therapeutics 63 265-311.

Barboni B, Turriani M, Galeati G, Spinaci M, Bacci ML, Forni M \& Mattioli M 2000 Vascular endothelial growth factor production in growing pig antral follicles. Biology of Reproduction 63 858-864.

Basini G, Bianco F, Grasselli F, Tirelli M, Bussolati S \& Tamanini C 2004 The effects of reduced oxygen tension on swine granulosa cell. Regulatory Peptides 120 69-75.

Basini G, Bianco F \& Grasselli F 2005 Epigallocatechin-3-gallate from green tea negatively affects swine granulosa cell function. Domestic Animal Endocrinology 28 243-256.

Basini G, Santini SE, Bussolati S \& Grasselli F 2007a The plant alkaloid sanguinarine is a potential inhibitor of follicular angiogenesis. Journal of Reproduction and Development 53 573-579.

Basini G, Bussolati S, Santini SE, Bianchi F, Careri M, Mangia A, Musci M \& Grasselli F 2007 b Antiangiogenesis in swine ovarian follicle: a potential role for 2-methoxyestradiol. Steroids 72 660-665. 
Becker CM, Rohwer N, Funakoshi T, Cramer T, Bernhardt W, Birsner A, Folkman J \& D'Amato RJ 2008 2-Methoxyestradiol inhibits hypoxiainducible factor- $1 \alpha$ and suppresses growth of lesions in a mouse model of endometriosis. American Journal of Pathology 172 534-544.

Carrillo S, Chamorro M, Rodriguez-Gago B, Alvarez MJ, Molina JI, Rodriguez-Barbosa A, Sanchez P, Ramirez A, Munoz J, Dominguez J et al. 2002 Isolation and characterization of immortalized porcine aortic endothelial cell lines. Veterinary Immunology and Immunopathology 89 91-98.

EURACHEM Guide 1998 The Fitness for Purpose of Analytical Methods: A Laboratory Guide to Method Validation and Related Topics, 1st English Edition 1.0-LGC (Teddington) Ltd. http://www.eurachem.ul.pt/.

Foresta C, Zuccarello D, Biagioli A, De Toni L, Prana E, Nicoletti V, Ambrosini G \& Ferlin A 2007 Oestrogen stimulates endothelial progenitor cells via oestrogen receptor-alpha. Clinical Endocrinology 67 520-525.

Fraser HM 2006 Regulation of the ovarian follicular vasculature. Reproductive Biology and Endocrinology 12 4-18.

Funk W, Dammann V \& Donnevert G 1995 Quality Assurance in Analytical Chemistry., New York: VHC Publishers.

Girsh E, Greger Y \& Meidan R 1995 Luteotrophic and luteolytic interactions between bovine small and large luteal-like cells and endothelial cells. Biology of Reproduction 52 954-962.

Grasselli F, Basini G, Tirelli M, Cavalli V, Bussolati S \& Tamanini C 2003 Angiogenic activity of porcine granulosa cells co-cultured with endothelial cells in a microcarrier-based three-dimensional fibrin gel. Journal of Physiology and Pharmacology 54 361-370.

Grow DR 2002 Metabolism of endogenous and exogenous reproductive hormones. Obstetrics and Gynecology Clinics of North America 29 425-436.

Guidance for Industry, Bioanalytical Method Validation 2001 US Department of Health and Human Services, Food and Drug Administration.

Ho SM 2004 Estrogens and anti-estrogens: key mediators of prostate carcinogenesis and new therapeutic candidates. Journal of Cellular Biochemistry 91 491-503.

Jaggers DC, Collins WP \& Milligan SR 1996 Potent inhibitory effect of steroids in an in vitro model of angiogenesis. Journal of Endocrinology 150 457-464.

Lin HL, Yang MH, Wu CW, Chen PM, Yang YP, Chu YR, Kao CL, Ku HH, Lo JF, Liou JP et al. 2007 2-Methoxyestradiol attenuates phosphatidylinositol 3-kinase/Akt pathway-mediated metastasis of gastric cancer. International Journal of Cancer 121 2547-2555.

Losordo DW \& Isner JM 2001 Estrogen and angiogenesis. Arteriosclerosis, Thrombosis, and Vascular Biology 21 6-12.

Mishra A \& Joy PK 2006 Effects of gonadotrophin in vivo and 2-hydroxyoestradiol-17beta in vitro on follicular steroid hormone profile associated with oocyte maturation in the catfish Heteropneustes fossilis. Journal of Endocrinology 189 341-353.
Neeman M, Abramovitch R, Schiffenbauer YS \& Tempel C 1997 Regulation of angiogenesis by hypoxic stress: from solid tumours to the ovarian follicle. International Journal of Experimental Pathology 78 57-70.

Raju U, Sepkovic DW, Miller WR, Dixon JM, Bradlow HL \& Levitz M 2000 Estrone and estradiol metabolism in vivo in human breast cysts. Steroids $\mathbf{6 5}$ 883-888.

Salama SA, Nasr AB, Dubey RK \& Al-Hendy A 2006 Estrogen metabolite 2-methoxyestradiol induces apoptosis and inhibits cell proliferation and collagen production in rat and human leiomyoma cells: a potential medicinal treatment for uterine fibroids. Journal of the Society for Gynecologic Investigation 13 542-550.

Salih S, Xu X, Veenstra TD, Duleba AJ, Fouad H, Nagamani M \& Al-Hendy A 2007 Lower levels of urinary 2-hydroxyestrogens in polycystic ovary syndrome. Journal of Clinical Endocrinology and Metabolism 92 3285-3291.

Sato Y 2006 Update on endogenous inhibitors of angiogenesis. Endothelium 13 147-155.

Shelhamer JH, Volkman DJ, Parrillo JE, Lawley TJ, Johnston MR \& Fauci AS 1985 Takayasu's arteritis and its therapy. Annals of Internal Medicine $\mathbf{1 0 3}$ 121-126.

Shimizu T \& Miyamoto A 2007 Progesterone induces the expression of vascular endothelial growth factor (VEGF) 120 and Flk-1, its receptor, in bovine granulosa cells. Animal Reproduction Science 102 228-237.

Spicer LJ \& Hammond JM 1989 Mechanism of action of 2-hydroxyestradiol on steroidogenesis in ovarian granulosa cells: interactions with catecholamines and gonadotropins involve cyclic adenosine monophosphate. Biology of Reproduction 40 87-95.

Spicer LJ, Kao LC, Strauss JF III \& Hammond JM 1990 2-Hydroxyestradiol enhanced progesterone production by porcine granulosa cells: dependence on de novo cholesterol synthesis and stimulation of cholesterol side-chain cleavage activity and cytochrome P450scc messenger ribonucleic acid levels. Endocrinology 127 2763-2770.

Van Veldhuizen PJ, Ray G, Banerjee S, Dhar G, Kambhampati S, Dhar A \& Banerjee SK 2008 2-Methoxyestradiol modulates beta-catenin in prostate cancer cells: a possible mediator of 2-methoxyestradiol-induced inhibition of cell growth. International Journal of Cancer 122 567-571.

Wijayagunawardane MP, Kodithuwakku SP, Yamamoto D \& Miyamoto A 2005 Vascular endothelial growth factor system in the cow oviduct: a possible involvement in the regulation of oviductal motility and embryo transport. Molecular Reproduction and Development 72 511-520.

Received in final form 3 July 2008

Accepted 6 July 2008

Made available online as an Accepted Preprint 25 July 2008 